\title{
Empathy influences how listeners interpret intonation and meaning when words are ambiguous
}

\author{
Núria Esteve-Gibert ${ }^{1,2} \cdot$ Amy J. Schafer ${ }^{3}$. Barbara Hemforth ${ }^{4} \cdot$ Cristel Portes $^{1} \cdot$ Céline Pozniak $^{4}$. \\ Mariapaola D'Imperio ${ }^{1,5}$
}

Published online: 3 January 2020

(C) The Psychonomic Society, Inc. 2020

\begin{abstract}
This study examines how individual pragmatic skills, and more specifically, empathy, influences language processing when a temporary lexical ambiguity can be resolved via intonation. We designed a visual-world eye-tracking experiment in which participants could anticipate a referent before disambiguating lexical information became available, by inferring either a contrast meaning or a confirmatory meaning from the intonation contour alone. Our results show that individual empathy skills determine how listeners deal with the meaning alternatives of an ambiguous referent, and the way they use intonational meaning to disambiguate the referent. Listeners with better pragmatic skills (higher empathy) were sensitive to intonation cues when forming sound-meaning associations during the unfolding of an ambiguous referent, and showed higher sensitivity to all the alternative interpretations of that ambiguous referent. Less pragmatically skilled listeners showed weaker processing of intonational meaning because they needed subsequent disambiguating material to select a referent and showed less sensitivity to the set of alternative interpretations. Overall, our results call for taking into account individual pragmatic differences in the study of intonational meaning processing and sentence comprehension in general.
\end{abstract}

Keywords Intonation processing $\cdot$ Individual differences $\cdot$ Empathy $\cdot$ Eye tracking $\cdot$ Intonational meaning $\cdot$ French $\cdot$ Homophone

An important aspect of language comprehension is that in the presence of the same linguistic elements, listeners can arrive at different interpretations of the message (e.g., Cain, Lemmon, \& Oakhill, 2004; Gandour, Wong, \& Hutchins, 1998; Swets, Desmet, Hambrick, \& Ferreira, 2007). Individual differences in language processing are widely documented in previous research (see reviews by Kidd, Donnelly, \& Christiansen, 2018; Münster \& Knoeferle, 2018), and yet what causes this variation is still not

Electronic supplementary material The online version of this article (https://doi.org/10.3758/s13421-019-00990-w) contains supplementary material, which is available to authorized users.

Núria Esteve-Gibert

nesteveg@uoc.edu

Aix Marseille Univ., CNRS, LPL, Aix-en-Provence, France

2 Estudis de Psicologia i Educació, Universitat Oberta de Catalunya (UOC), Barcelona, Spain

3 University of Hawaii at Mānoa, Hawaii, Honolulu, HI, USA

4 Laboratoire de Linguistique Formelle, CNRS, Université Paris Diderot, Paris, France

5 Rutgers University, New Brunswick, NJ, USA understood. We know that cognitive capacities like working memory and executive functions are linked to individual variation in language processing tasks (e.g., Friedman et al., 2008; Just $\&$ Carpenter, 1992; Swets et al., 2007). Here, we explore another potential source of individual differences in utterance interpretation: pragmatic abilities, and more specifically, empathy, as it relates to listeners' ability to respond to intonational disambiguation of lexical ambiguity.

From a comprehender's viewpoint, empathy is an essential tool for language processing because it allows one to understand the intentions of others, predict their behavior, and experience an emotion triggered by others' emotions (Baron-Cohen \& Wheelwright, 2004). Empathy is part of the set of pragmatic abilities that is generally known as theory of mind (ToM), mindreading, mentalizing, or perspective-taking (Baron-Cohen, 2011; Carruthers, 2009; Frith \& Frith, 2003). Researchers have traditionally categorized two dimensions of empathy that in practice are tightly related and sometimes difficult to distinguish: affective empathy (to be emotionally aligned with the interlocutor) and cognitive empathy (to recognize and understand what an interlocutor feels or thinks; Baron-Cohen \& Wheelwright, 2004; Shamay-Tsoory, Aharon-Peretz, \& Perry, 2009; Zaki \& Ochsner, 2012). Empathy is needed to comprehend others' motives behind 
their actions, including understanding verbal interactions that convey literal as well as nonliteral meaning (Li, Jian, Yu, \& Zhou, 2014; Rockwell, 2003; Van den Brink et al., 2012). Individual empathy is thus a potential source of variability in language comprehension, especially when linguistic meaning is nonliteral.

Speakers' expression of feelings and thoughts is not limited to lexical-semantic cues. Speakers also use intonational cues of speech (i.e., the melodic variation at the utterance level) to express pragmatic meaning, mental states, commitment toward the content of an utterance, and to structure information in speech (Ladd, 1996/2008; Pierrehumbert \& Hirschberg, 1990, for English; Chen, Gussenhoven, \& Rietveld, 2004, for Dutch; see Prieto, 2015, for a review). In a language such as English or French, intonation contours are formed by combinations of pitch accents (i.e., tonal movements associated with prominent words in the sentence) and edge tones (i.e., melodic targets associated with the edges of intonational domains) that together transmit the speaker's intended meaning.

The speaker's choice of pitch accents and edge tones in each utterance is a key contributor to its pragmatic value. In past decades, an effort has been made to describe the intonational phonology of many languages and its contribution to pragmatic meaning (Frota \& Prieto, 2015; Jun, 2005; Pierrehumbert \& Hirschberg, 1990). For instance, in many languages high tones at the end of the phrase signal a yes-no question, and a final high tone preceded by a rising pitch accent supports a counterexpectational interpretation in languages such as French or Spanish (Delais-Roussarie et al., 2015; Estebas-Vilaplana \& Prieto, 2010). Similarly, in English, new contrastive referents in the discourse are produced with a combination of a rising pitch accent and a low edge tone, and listeners reliably use this intonational information to process and even to anticipate the referent of the utterance (e.g., Braun \& Tagliapietra, 2010; Cutler, Dahan, \& van Donselaar, 1997; Dahan, Tanenhaus, \& Chambers, 2002; Ito \& Speer, 2008).

Importantly, individuals vary in how they process intonational cues and how they use them to infer pragmatic meaning (Bishop, Chong, \& Jun, 2015; Diehl, Bennetto, Watson, Gunlogson, \& McDonough, 2008; Jun \& Bishop, 2014; Katz \& Selkirk, 2011; Portes, Beyssade, Michelas, Marandin, Champagne-Lavau, 2014; Ward \& Hirschberg, 1988). Portes et al. (2014) found that listeners can have different interpretations for the very same tonal configuration in French, while Bishop (2016) and Bishop and Kuo (2016) found that listeners rely on distinct cues (pitch accent, edge tones, or duration cues) to interpret the syntactic structure of a relative clause.

Only recently, researchers have started investigating the reasons behind individual variability in intonation processing. One factor could be key: individual pragmatic skills. Jun and Bishop (2014) assessed the autistic traits of normal adults and found they correlated with their use of intonational cues to syntactic processing. Specifically, Bishop (2016) observed that pragmatically skilled individuals use prosodic prominence and pitch accent type to interpret whether a relative clause has high or low attachment, while less pragmatically skilled individuals tend to rely mainly on subsequent boundary tone and durational information.

Previous results in the semantics/pragmatics literature had already reported individual variability in the interpretation of the quantifier some. Some listeners prefer a literal/semantic interpretation of some (as "at least some and possibly all"), whereas others choose a pragmatically enriched interpretation (as "only some but not all"; Bott \& Noveck, 2004; Degen \& Tanenhaus, 2015; Nieuwland, Ditman, \& Kuperberg, 2010; Zhao, Liu, Chen, \& Chen, 2015). Nieuwland et al. (2010) found that this difference was correlated with their individual pragmatic skills. In a series of visual-world eye-tracking experiments, Degen and Tanenhaus (2015) observed that "semantic" listeners did not resolve the ambiguity immediately, but waited for subsequent disambiguating material, and once their interpretational choice was made, they committed to it and did not reconsider possible alternatives; instead, "pragmatic" listeners started constructing the enriched meaning immediately after the presentation of the ambiguous expression, while showing delayed looks at the target due to lack of commitment to one of the possible alternative meanings.

Altogether, previous studies suggest that individuals that are more pragmatically skilled can be expected to be more sensitive to a cue (e.g., intonation) that conveys pragmatic meaning, and that they will more likely activate and consider all the potential interpretations of an utterance. The goal of the present study is to investigate individual variability in processing the intonation-meaning mapping, testing listener's empathy as a relevant factor in this variation. We ask two main research questions: (1) Does individual empathy affect how listeners use intonation cues to resolve temporary meaning ambiguities? (2) Does individual empathy influence the selection of alternatives in lexically ambiguous words?

Based on previous evidence, we formulated two main hypotheses. First, individuals with higher empathy (better pragmatic skills) will be more sensitive to intonational cues that can be used to infer the meaning of an ambiguous referent, as opposed to less empathically skilled individuals. Second, compared with less empathically skilled individuals, listeners with higher empathy will be more likely to activate and maintain all the potential alternative interpretations of temporary ambiguous referents.

To test these hypotheses, we designed a visual-world eyetracking task in which Speaker A uttered a suggestion about a referent, and Speaker B either confirmed or rejected that guess. We recorded the listeners' looking patterns toward a target referent during Speaker B's response, and correlated them with the listeners' empathy level.

For convenience, here we preview key aspects of our design and the comparisons in our analysis. Three critical 
conditions were manipulated: two in which Speaker B's response was lexically ambiguous, but intonation could be used to infer either a rejection (contrast-test condition) or a confirmation (confirmation-test condition) meaning, and one condition in which the response was nonambiguous at the intonational and lexical levels (contrast-control condition). Additionally, two additional filler conditions were created with unambiguous referents in both Speaker A's guess and Speaker B's response (confirmation-filler condition; contrast-filler condition).

To assess listeners' use of intonation to resolve meaning ambiguities, we will first compare the contrast-test and confirmation-test conditions because they were lexically identical, but differed in the intonation contour that was used, and distinct eye-fixation patterns would indicate the listeners' use of intonation to infer meaning. Second, we will compare the contrast-test condition to contrast-control condition to assess the listeners' patterns when intonation is accompanied by disambiguating lexical cues, given that the control condition was lexically unambiguous. Finally, additional comparisons between the critical and the filler conditions will be used to inspect the effect of the overall presence of ambiguity in our stimuli and to contextualize the findings from the critical conditions.

\section{Method}

\section{Participants}

Sixty native speakers of French (14 males, age ranging from 19 to 48 years) were recruited in the Paris area from the French RISC database (http://www.risc.cnrs.fr). From these, six participants were excluded due to technical errors $(N=2)$ or because they only looked at the center of the screen during the experimental trials $(N=4)$. The final sample included 54 participants (12 males; mean age 26 years, age ranging from 19 to 48 years). They all received $10 €$ for their participation in the study, gave informed consent, and reported no history of speech or hearing problems.

\section{Experimental task}

Using the visual-world eye-tracking paradigm (Tanenhaus, Spivey-Knowlton, Eberhard, \& Sedivy, 1995), listeners were tested in an experiment evoking a card-guessing game in which homophones were used. In this game, Player A made suggestions about an image on Player B's cards (e.g., "I think you have a female duck"), and Player B responded either confirming or contradicting Player's A suggestions by indicating the right referent (e.g., "I have a female duck, indeed, the animal"/"I have a stick, instead, to walk"). Three features were crucial in this design. First, the target referent was a homophone and thus semantically ambiguous (in French, both "female duck" and "walking stick" are equally pronounced as $/ \mathrm{kan} /$, though the orthography is different, i.e., cane vs. canne). Second, Player A's suggestions provided a discourse context that could constrain the possible meaning interpretations, as they were accompanied by A showing $\mathrm{B}$ a picture of one of the alternative interpretations of the homophone (in the previous example, for instance, a picture of a female duck). Third, Player B's responses were segmentally identical in the critical test conditions before the unfolding of a disambiguating sequence (i.e., either bien sûr "of course/indeed" + additional disambiguating material or plûtot "instead/actually" + additional disambiguating material). Crucially, though, despite the presence of lexical ambiguity, the intonation contour indicated whether contradiction or confirmation was intended.

\section{Materials}

\section{Critical trials}

Eighteen sets of critical sentences, each composed of a suggestion followed by a response, were created to simulate a dialogue that might occur while playing a simple card game (see Table 1 for a summary and exemplification of the composition of critical sentences).

Auditory stimuli Auditory stimuli of Player A's suggestions had the form of Je pense que tu as un/e ("I think you have a/ an [critical word]"), with a homophone as the critical word in phrase-final position. For instance, Player A would say, Je pense que tu as une [cane] ("I think you have a [female duck]"), cane ("female duck") being homophonous in French with canne ("walking stick"), both being pronounced as $/ \mathrm{kan} /$. All homophonous words had two possible meaning alternatives. Each suggestion utterance was followed by a response utterance. The response stimuli had the form of J'ai un/e ("I have a/an") + ambiguous homophonous critical word + disambiguating sentence context. For instance, after the previous Player A's suggestion, Player B would respond either J'ai une cane, bien sûr, l'animal ("I have a female duck, indeed, the animal") or J'ai une canne, plutôt, pour marcher ("I have a walking stick, instead, to walk). Crucially, the "I have a/an + [critical word]" portion of the response was uttered with one of two possible intonation contours: (1) a falling pitch movement (labeled as LHiL* L-L\% in French-ToBI), characterized by an accentual fall preceded by an initial phrasal rise, which is generally associated with a confirmation meaning, or (2) a rising-falling pitch movement (labeled as $\mathrm{LH}^{*} \mathrm{~L}-\mathrm{L} \%$ ) which has been mostly associated with a contrast of beliefs between interlocutors (Delattre, 1966; Jun \& Fougeron, 2000; Portes, 2004; Portes \& Reyle, 2014). The first intonation condition (called "confirmation-test condition") was intended to trigger a confirmation interpretation, and thus listeners were 
Table 1 Summary and examples of all test and filler trial conditions

\begin{tabular}{|c|c|c|c|c|}
\hline Type & & Condition & Speaker's A suggestion & Speaker's B response \\
\hline \multirow[t]{3}{*}{ Critical trials } & \multirow[t]{2}{*}{ Test } & Confirmation-test & $\begin{array}{l}\text { Je pense que tu as un/e }\left[\mathrm{CW}_{\mathrm{HOM}}\right] \\
\text { Je pense que tu as une cane } \\
\text { 'I think you have a female duck' }\end{array}$ & 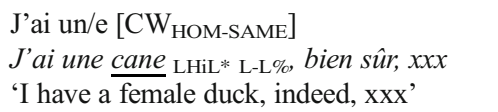 \\
\hline & & Contrast-test & $\begin{array}{l}\text { Je pense que tu as un/e }\left[\mathrm{CW}_{\mathrm{HOM}}\right] \\
\text { Je pense que tu as une cane } \\
\text { 'I think you have a female duck' }\end{array}$ & $\begin{array}{l}\text { J'ai un/e }\left[\mathrm{CW}_{\text {HOM-DIFFERENT }}\right] \\
\text { J'ai une canne } \\
\text { 'I have a stick, instead, xxx' }\end{array}$ \\
\hline & \multirow[t]{3}{*}{ Control } & Contrast-control & $\begin{array}{l}\text { Je pense que tu as un/e }\left[\mathrm{CW}_{\mathrm{HOM}}\right] \\
\text { Je pense que tu as une cane } \\
\text { 'I think you have a female duck' }\end{array}$ & $\begin{array}{l}\text { J'ai un/e }\left[\mathrm{CW}_{\mathrm{NONHOM}}\right] \\
\text { J'ai une poupée } \mathrm{LH}^{*} \mathrm{~L}-\mathrm{L} \% \text {, plutôt, } x x x \\
\text { 'I have a doll, instead, xxx' }\end{array}$ \\
\hline \multirow[t]{2}{*}{ Filler trials } & & Confirmation-filler & $\begin{array}{l}\text { Je pense que tu as un/e }\left[\mathrm{CW}_{\text {NONHOM }}\right] \\
\text { Je pense que tu as une bouteille } \\
\text { 'I think you have a bottle' }\end{array}$ & $\begin{array}{l}\text { J'ai un/e }\left[\mathrm{CW}_{\text {NONHOM-SAME }}\right] \\
J^{\prime} \text { 'ai une bouteille }{ }_{\text {LHiL* L-L\%, }} \text {, bien sûr, } x x x \\
\text { 'I have a bottle, indeed, xxx' }\end{array}$ \\
\hline & & Contrast-filler & $\begin{array}{l}\text { Je pense que tu as un/e }\left[\mathrm{CW}_{\text {NONHOM }}\right] \\
\text { Je pense que tu as une fleur } \\
\text { 'I think you have a flower' }\end{array}$ & $\begin{array}{l}\text { J'ai un/e }\left[\mathrm{CW}_{\text {NONHOM-DIFFERENT }}\right] \\
\text { J'ai une figue } \mathrm{LH}^{*} \mathrm{L-L} \% \text {, plutôt, } x x x \\
\text { 'I have a fig, instead, xxx' }\end{array}$ \\
\hline
\end{tabular}

Note. $\mathrm{CW}=$ critical word

expected to fixate the figure depicting the homophone suggested in the previous scene. The second intonation condition (called "contrast-test condition") was intended to trigger a contrast interpretation, and thus we anticipated that listeners would show increased fixations to the alternative meaning of the homophone. A third type of response was also created to serve as control utterances, in which the critical word in the response was not a homophone and therefore not semantically ambiguous. In this condition, called "contrast-control condition," responses were produced with the same rising-falling pitch movement as in the contrast-test condition, signaling a contrast with respect to the suggestion scene. A total of 18 critical trials were created (six in the confirmation-test condition, six in the contrast-test condition, and six in the contrastcontrol condition).

Table 1 summarizes and exemplifies each condition, and Fig. 1 shows pitch curves for the three possible critical responses. Crucially, confirmation-test and contrast-test responses were lexically identical before the disambiguating sentence context was presented, and so only intonation could indicate whether the homophone referred to the suggested or the alternative meaning (prior to the end of the critical word).

Stimuli were recorded in a soundproof chamber by two prosodically trained female speakers. One female speaker produced suggestions using the same intonation contour in all sentences. The other female speaker first produced all sentences with the confirmatory contour, and then repeated the set with the contrast contour. Using Praat (Boersma \& Weenink, 2012), all stimuli were annotated for duration (in milliseconds) and mean F0 values (in $\mathrm{Hz}$ ) in the region preceding the critical word, the critical word, and the clarification phrase, and the overall mean duration and mean F0 values were then calculated per critical condition. The results of one-way ANOVAs on durations and mean F0 values for the critical responses (see Table 2) revealed that there were indeed robust phonetic differences between the two tunes. More specifically: (1) the region preceding the critical word was significantly longer and had higher F0 values in the confirmation-test than in the contrast-test and contrast-control conditions (with no differences between the latter two); (2) the critical word in the confirmation-test condition was equally long, but with lower pitch than in the contrast-test and contrast-control conditions (the latter two differing in both duration and pitch); and (3) the clarification phrase was shorter and with lower pitch in the confirmation-test condition than in the contrast-test condition, the two contrast conditions not differing between each other in any parameter.

Visual stimuli The visual display accompanying the suggestion auditory stimulus depicted the subordinate meaning of that homophone (see Fig. 2, left panel), thus providing disambiguating contextual cues by which a less frequent interpretation of the homophone was asserted. Frequency scores were determined through the Lexique database (New, Pallier, Brysbaert, \& Ferrand, 2004; see Appendix A for a complete list of the homophone pairs). Given that previous research testing homophones in visual-world experiments has found that listeners activate the dominant interpretation even in subordinate-biased contexts (Chen \& Boland, 2008; Huettig \& Altmann, 2007), displaying the subordinate interpretation of the homophone allowed us to ensure that our participants would activate both alternative interpretations. ${ }^{1}$

\footnotetext{
${ }^{1}$ The other possibilities would have been to use both the subordinate and the dominant meanings as primes, or to always prime participants with the dominant interpretation. These two options would have more strongly biased participants' responses toward a dominant alternative: In the first case, we would not have been able to control that in all trials both interpretations would be activated to the same extent; in the latter case, we would not have been able to ensure that participants would also activate the subordinate interpretation.
} 

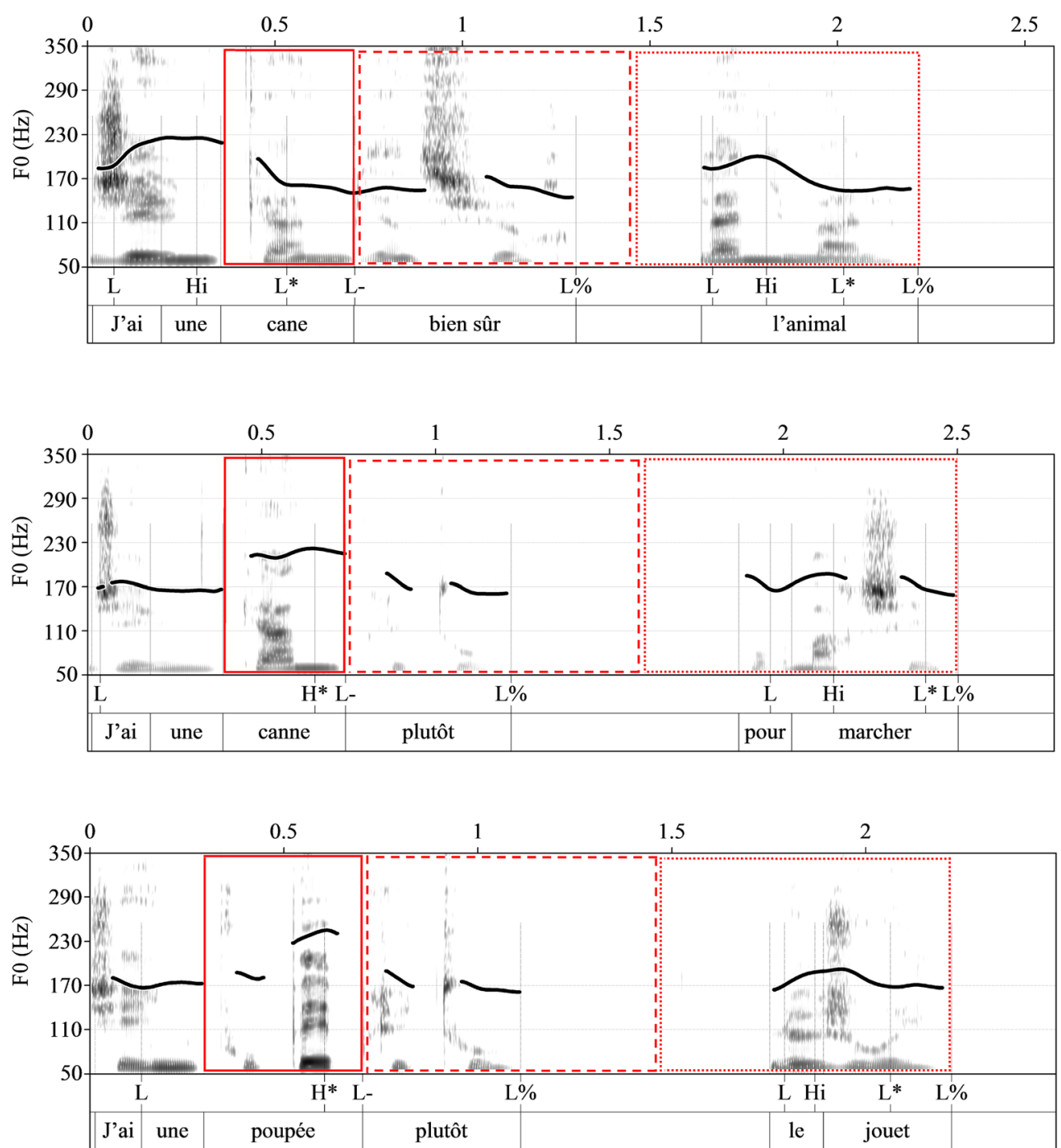

Fig. 1 Spectrograms and pitch curves of Player B's responses in each critical condition. Top panel displays the confirmation-test condition ( $J^{\prime} a i$ une cane, bien sûr, l'animal - "I have a female duck, indeed, the animal"). The middle panel displays the contrast-test condition (J'ai une canne, plutôt, pour marcher - "I have a walking stick, instead, for walking"). The lower panel displays the contrast-control condition ( $J^{\prime}$ ai une poupée, plutôt, le jouet-"I have a doll, instead, the toy"). The solid rectangle indicates the temporal limits of the critical word; the dashed rectangle indicates the temporal limits of the first half of the disambiguation phase; the dotted rectangle indicates the temporal limits of the second half of the disambiguation phase
The visual display for the auditory response stimulus presented four objects, one of which always matched the target referent of the response (see Fig. 2, right panel). There were four areas of interest in each display, corresponding to the division of the screen into four quadrants. The bottom left position always depicted the previous suggestion, and so it always matched the previously suggested meaning (the target homophone for the confirmatory responses, but the competitor in contrast responses). The other three positions presented the image depicting the alternative meaning of the homophone pair (the target image for the contrast-test condition) and two images depicting a nonhomophone referent (one of which was the target in the contrast-control condition).
Note that in the scene configuration the subordinate interpretation of the homophone was always located in the bottomleft position, used for all suggested images. This display was chosen for several reasons. First, it allowed to better test the influence of sentence context, as participants could more easily anticipate the image depicting the interpretation primed by this sentence context without the need to first explore the entire visual display. Second, it allowed participants to anticipate the position of the suggested referent, and therefore we could more easily test whether the information from the intonation contour caused a rapid switch from the suggested interpretation to the alternative one. The assignment of images to the other three positions was counterbalanced. 
Table 2 Mean duration and pitch values ( $S D$ in parentheses) for each critical condition during the critical word (CW), before it ("J'ai un/e"), and after it (during the clarification phrase)

\begin{tabular}{|c|c|c|c|c|c|c|}
\hline \multirow[b]{2}{*}{ Condition } & \multicolumn{2}{|l|}{ J'ai un/e } & \multicolumn{2}{|l|}{$\mathrm{CW}$} & \multicolumn{2}{|c|}{ Clarification phrase } \\
\hline & Dur in ms & $\mathrm{F} 0$ in $\mathrm{Hz}$ & Dur in ms & $\mathrm{F} 0$ in $\mathrm{Hz}$ & Dur in $\mathrm{ms}$ & $\mathrm{F} 0$ in $\mathrm{Hz}$ \\
\hline Confirmation-test & $348(6.93)$ & $208(1.35)$ & $364(15.96)$ & $169(1.56)$ & $1970(32.86)$ & $165(0.55)$ \\
\hline Contrast-test & $323(8.42)$ & $169(1.15)$ & $350(15.12)$ & $227(3.29)$ & $2137(52.57)$ & $172(0.89)$ \\
\hline Contrast-control & $304(8.89)$ & $167(0.82)$ & $413(20.11)$ & $212(2.67)$ & $2113(39.23)$ & $171(0.96)$ \\
\hline $\begin{array}{l}\text { Conf-test vs. contr-test } \\
F \text { value }(d f=35) \text { : }\end{array}$ & $5.09 *$ & $480.81 * * *$ & .44 & $250.38 * * *$ & $8.59 * *$ & $53.87 * * *$ \\
\hline $\begin{array}{l}\text { Conf-test vs. contr-cont } \\
F \text { value }(d f=35)\end{array}$ & $14.61 * *$ & $669.02 * * *$ & 3.62 & $193.53 * * *$ & 3.44 & $33.61 * * *$ \\
\hline Contr-test vs. contr-cont $F$ value $(d f=35)$ : & 2.28 & 2.103 & $6.36^{*}$ & $11.976^{* *}$ & 1.75 & .87 \\
\hline
\end{tabular}

${ }^{*} p<.05 . * * p<.01 . * * * p<.001$.

\section{Filler trials}

Thirty-six filler suggestion-response pairs were also created. Filler pairs had the same form as critical pairs (Je pense que tu as un/e $X$ ["I think you have a/an X"] _J'ai un/e X ["I have a/ an $X$ "]) but included nonhomophone words in the critical positions of the suggestion and response parts.

Auditory stimuli There were two types of fillers: confirmationfiller pairs $(N=21)$, with a nonhomophone word in the suggestion and the same nonhomophone as the critical word in the response, produced with a $\mathrm{LHiL}^{*} \mathrm{~L}-\mathrm{L} \%$ falling confirmation intonation; and contrast-filler pairs $(N=15)$, with a nonhomophone in the suggestion and a different nonhomophone as the critical word in the response, produced with a $\mathrm{LH}^{*} \mathrm{~L}-\mathrm{L} \%$ rising-falling contrast intonation. There were fewer filler-contrast pairs than filler-confirmation pairs to balance confirmation and contrast responses across the experiment. Thus, in total, 27 response trials in the experiment used confirmation intonation for correct card guesses (6 in the critical responses and 21 in the filler responses), and 27 response trials used contrast intonation for incorrect guesses (12 in the critical responses and 15 in the filler responses).

Visual stimuli The visual display in filler trials was the same as in critical trials, except for the fact that while the bottom-left position depicted the previous suggestion (like in critical trials), the other three positions now depicted three nonhomophone referents (one of which was the target in the contrast-filler condition). Like in critical trials, there were four areas of interest in each display, corresponding to the division of the screen into four quadrants.

\section{Procedure}

Prior to the eye-tracking task, all participants completed a selfreported Empathy Quotient (EQ) questionnaire (Baron-Cohen
\& Wheelwright, 2004) to tap into their individual empathy skills, and their individual scores were used as a predictor in the subsequent analyses. Various tools exist to assess individual empathy and pragmatic skills, such as false-belief tasks in children (Baron-Cohen, Leslie, \& Frith, 1985; Wimmer \& Perner, 1983) or self-reported questionnaires in adults (Autism Quotient Questionnaire, Baron-Cohen, Wheelwright, Skinner, Martin, \& Clubley, 2001; EQ Questionnaire, Baron-Cohen \& Wheelwright, 2004; Interpersonal Reaction Index Questionnaire, Davis, 1980). The EQ questionnaire is a tool designed to be used with adults of normal intelligence and has been successfully validated with individuals with high-functioning autism and Asperger syndrome. It contains 60 forced-choice questions (40 test items and 20 fillers) in which responders score 1 point if reporting an empathic behavior mildly or 2 points if reporting the behavior strongly. Test items evaluate both the affective and the cognitive component of empathy, and, as the authors state, no distinction is made between categories because both components co-occur and cannot be disentangled. The EQ questionnaire has been successfully used in previous studies on language production and processing (Chu, Meyer, Foulkes \& Kita, 2014; Foucart et al., 2015; Van den Brink et al., 2012).

Also, before the experiment, we determined the subject's dominant eye by applying the Miles test (Miles, 1929). Only eye movements from the dominant eye were registered. Participants were seated in front of an EyeLink II eyetracking system (distance between participants and screen: ca. $80 \mathrm{~cm}$ ), connected to two loudspeakers, before game instructions were given to them. In the instructions they were told that they would see a scene in which one player would try to guess the other player's cards, and that they would hear the first player's suggestion and then the other player's response, either confirming or contradicting the suggestion. Participants first saw the suggestion display where Player A showed a card with an object to Player B and then the response display. A drift correction with a fixation point at the middle of the screen 

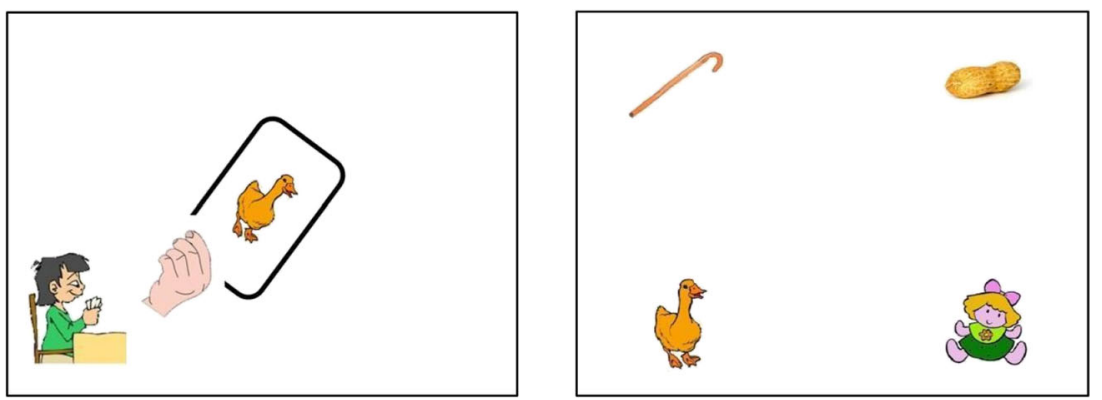

Fig. 2 Example of a visual display accompanying suggestions (left) and responses (right). In the right panel, the bottom-left image is the suggested meaning of the homophone, the top-left image is the alternative meaning of the homophone, and the other two images are unrelated distractors

was performed between the suggestion display and the response display to make sure that participants always started from the same position. The visual displays were presented for $3.5 \mathrm{~s}$ in suggestion scenes and for $4.5 \mathrm{~s}$ in response scenes. Their corresponding auditory stimuli were synchronized with the onset of the visual displays. The interval between the suggestion and the response display was self-paced by participants and depended on the time it took them to fixate the drift-correcting fixation point.

To ensure participants' attention to the eye-tracking task, after listening to the entire response, participants were asked to press one of four keys on the number pad matching the position of the image on the screen $(1=$ top left; $2=$ top right; $3=$ bottom left; $4=$ bottom right) corresponding to their response. No time pressure was put on the picture choice to prevent the participants looking at the keys before the trial ended.

Three practice trials preceded a five-point calibration and the subsequent experiment. Each participant was presented with a total of 54 (18 critical and 36 filler) trials. Critical and filler trials appeared in randomized order during the experiment. Test conditions were counterbalanced across participants in a Latin square design and resulted in three different lists so that each trial condition changed according to the list. Participants were randomly assigned to the lists.

\section{Analysis of the eye-tracking data}

We used the R environment and the RStudio interface for the analysis. We specifically used the following packages: EyetrackingR (Dink \& Ferguson, 2015), lme4 (Bates, Maechler, Bolker, \& Walker, 2014), ggplot2 (Wickham, 2016), lmerTest (Kuznetsova, Brockhoff, \& Christensen, 2017), and optimx (Nash \& Varadhan, 2011). Growth curve analyses (Mirman, 2014; Mirman, Dixon, \& Magnuson, 2008) were run. These analyses are especially suitable when including time as a continuous predictor and when changes over time are predicted (as is the case in our study, where looks to the images were expected to change during the unfolding of the utterance). All data and analysis code used for this paper are available on the Open Science Framework (https://osf.io/ nwe7s).

The dependent variable was the empirical logit of looks to the image depicting the suggested word versus looks to the other three areas of interest in the visual scene. $^{2}$ Looks to the suggested image are not independent of looks to the other images at a given time point, because only one image can be fixated at a time in a given trial. Given that there can be visual biases to particular images or locations in the visual scene, we follow common practice in the visual-world paradigm literature and use a dependent measure based on the ratio of looks to the suggested image versus looks elsewhere. Trials with more than $25 \%$ track loss were excluded. The independent variables were time, condition (five levels: confirmation-test, contrast-test, contrast-control, confirmation-filler, and contrast-filler), empathy (as a continuous variable), and time window (three levels: $0-675 \mathrm{~ms} ; 675-1,400 \mathrm{~ms} ; 1,400-1,900 \mathrm{~ms})$. The $0-675$ $\mathrm{ms}$ time window corresponds to the processing of the critical word; the $675-1,400-\mathrm{ms}$ time window corresponds to the first portion of subsequent sentence disambiguation; the 1,400-1,900-ms time window corresponds to the second portion of the disambiguating sentence. We applied mean centered coding for all independent variables. When applicable, random variables included a by-item random slope and a by-participant random slope for the interaction of condition and time window (Barr, Levy, Scheepers, \& Tily, 2013). We enforced zero correlations between random effects in order to avoid overparameterization or false convergence (Bates, Kliegl, Vasishth, \& Baayen, 2015).

Two primary comparisons were applied. Comparison 1 (confirmation-test vs. contrast-test) tested the listeners' use

\footnotetext{
${ }^{2}$ Empirical logits were calculated via the EyetrackingR package using the following function: "make_time_sequence_data(data, time_bin_size $=50$, predictor_columns $=\mathrm{c}($ "Conditions", "Empathy", "Time_windows"), aois $=$ c("suggested"))
} 
of intonation to process meaning, and Comparison 2 (contrasttest vs. contrast-control) tested the listeners' processing of disambiguating lexical cues next to intonation, versus intonation alone. To supplement these, two additional comparisons were applied: Comparison 3 (contrast-control vs. contrast-filler) and Comparison 4 (confirmation-test vs. confirmation-filler) served as a test of the overall effect of ambiguity in the suggestion and response stimuli.

The procedure was the same for each comparison. First, we determined the model with the best-fit orthogonal polynomial function of time, following Mirman (2014). We only included orthogonal polynomial functions that statistically improved model fit (linear time for Comparisons 1, 2, and 4; quadratic time for Comparison 3 ). We then kept the same polynomial orthogonal function of time for the subsequent analyses (results of all the time models are available in Appendix B). Second, we ran an inclusive model with all the independent variables (time, condition, empathy, and time windows). If the variable time windows interacted with empathy and/or condition, we then looked at main effects and interactions within those relevant time windows. In these subsequent analyses within the relevant time windows, the independent variables were time, condition, and empathy. The $p$ values of the initial inclusive model and of the four comparisons were corrected using the Holm-Bonferroni approach. Only significant results are reported here; complete results of the eye-tracking data are available in Appendix C.

\section{Results}

\section{Picture choice}

Participants pressed the correct key representing the position of the target image in $97.9 \%$ of the trials $\mathbf{( 9 8 . 8 \%}$ of the filler trials and $96.4 \%$ of the critical trials). A logistic regression model indicated that the accuracy of picture choice was not significantly affected by condition (intercept: $\beta=.98, t=92.39, p<.001$; confirmation-test: $\beta=-.01, t=-.11, p=.911$; contrast-test: $\beta=$ $-.02, t=-.09, p=.923$; contrast-control: $\beta=.01, t=.53, p=.59$; confirmation-filler: $\beta=-.01, t=-.05, p=.962)$ nor by participants' empathy score $(\beta=.01, t=.37, p=.714)$, neither did the interaction between these two factors reach significance (confirmation-test:empathy: $\beta=-.01, t=-.21, p=.837$; contrast-test: $\beta$ $=.01, t=.24, p=.814$; contrast-control: $\beta=-.01, t=-.19, p=$ .84 ; confirmation-filler: $\beta=-.01, t=-.46, p=.648)$. These results indicate that participants were attentive to the task, irrespective of empathy skills, trial type, and intonation condition.

\section{Eye movements}

Figure 3 shows raw fixation proportions every $50 \mathrm{~ms}$ to the image depicting the suggested word (the target in the confirmation conditions) out of looks to all areas of interest (AoIs) in the five filler and test conditions included in the study. Two panels are displayed: one for participants with higher empathy and one for participants with lower empathy (see footnote 3 ).

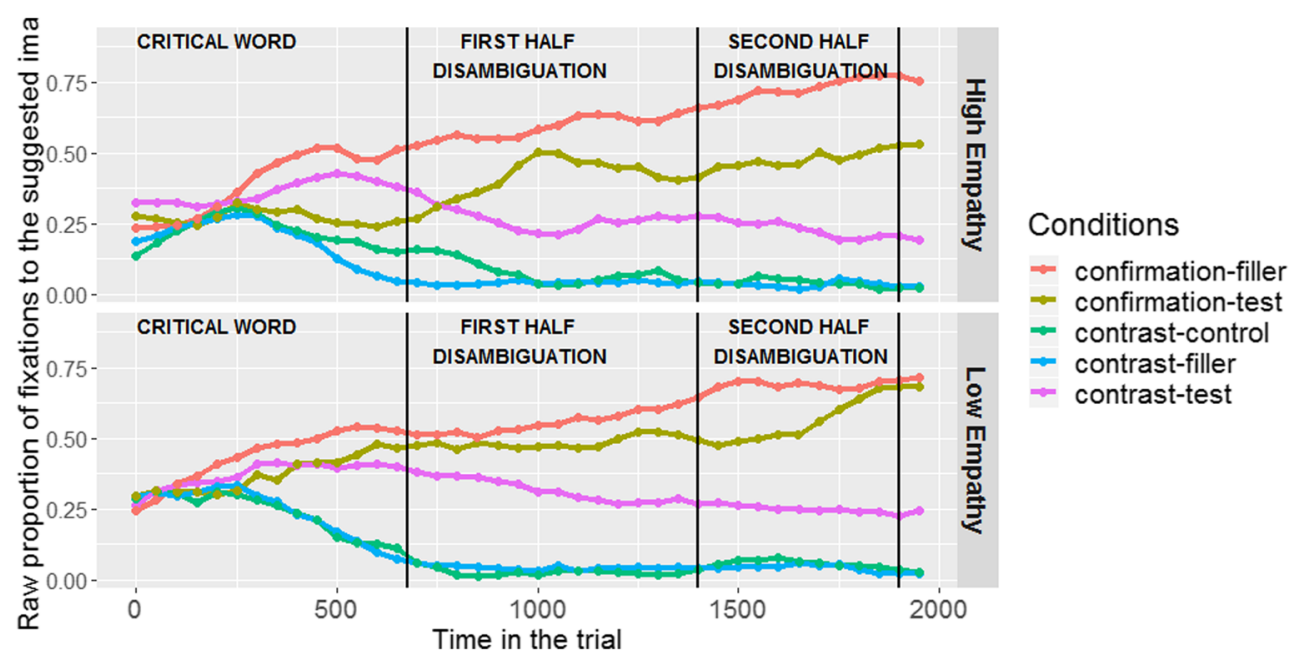

Fig. 3 Raw proportion of fixations to the suggested image across critical conditions and time (ms), averaged across items and aligned to the onset of the critical word. Upper panel: Proportion of fixations for highempathy participants. Lower panel: Proportion of fixations for lowempathy participants. While empathy is a continuous variable in the analyses, two groups are displayed in Fig. 3 (median split) to better illustrate participants' patterns. Listeners in the high-empathy group had a score in the EQ Questionnaire that was higher than the aggregated mean $\left(M_{\text {score }}=\right.$ 51 , range from 45 to $72 ; N=27,26$ females and one male), and low- empathy listeners had a score lower than the mean $\left(M_{\text {score }}=37\right.$, range from 21 to $44 ; N=27,16$ females and 11 males). The critical word time window corresponds to the listeners' gaze patterns during the processing of the referent in the response (solid rectangle in Fig. 1). The first half of disambiguation and second half of disambiguation time windows correspond to the listeners' gaze patterns during the first and second portions of subsequent disambiguating material, respectively (dashed and dotted rectangles in Fig. 1) 
Fixation proportions are aligned to the onset of the critical word. We assume that it takes about $225 \mathrm{~ms}$ for the eyes to program a saccade in reaction to a linguistic stimulus (Allopenna, Magnuson, \& Tanenhaus, 1998; Altmann \& Kamide, 2004; Matin, Shao, \& Boff, 1993; Salverda, Kleinschmidt, \& Tanenhaus, 2014); hence, the region depicting eye fixations in response to the material in the critical word starts (conservatively) at $0 \mathrm{~ms}$ (onset of the critical word) and continues until $675 \mathrm{~ms}$ (the average duration of critical words across all five conditions was $450 \mathrm{~ms}$ ).

The two panels in Fig. 3 reveal that before processing the critical word, the suggested image received around $25 \%$ of the total looks in all conditions and empathy values. During critical word processing, we observe that the presence of lexical ambiguity influenced the listeners' gaze patterns: As soon as a nonambiguous word was processed, listeners looked at the target AoI (the suggested image in confirmation-filler, and the other AoI in contrast-filler and contrast-control conditions); instead, when an ambiguous response was processed, listeners' patterns varied across empathy groups (less empathic individuals looked at the suggested image around $40 \%$ of the time in the confirmation-test and contrast-test conditions, but highly empathic individuals looked at the suggested image around $25 \%$ of the time in the confirmation-test condition, but $40 \%$ of the time in the contrast-test condition).

Once the ambiguous target referent started being segmentally disambiguated (first portion of the disambiguation), all participants looked at the suggested image more in the confirmation-test condition than in the contrast-test condition (as expected), with finer differences across empathy groups: gaze shifts to the target image are sharper in the high-empathy group, but milder in the low-empathy group. This time period also reveals an influence of empathy when the critical word had been ambiguous in the suggestion scene, but unambiguous in the response (contrast-control condition): low-empathy individuals barely looked at the suggested image (the expected behavior), but high-empathy individuals still direct some looks at it.

Looking patterns during the second portion of the disambiguation region are very similar across empathy groups, but still a slight difference can be observed: Individuals with lower empathy scores reached the target gaze behavior more accurately (the suggested image received around $75 \%$ of total looks in the confirmation-test condition), while individuals with higher empathy still seem to fixate the alternative AoI (the suggested image received only around $50 \%$ of total looks in the confirmation-test condition). This is interesting because at this point listeners had already perceived enough segmental material to undoubtedly disambiguate the target. These observed patterns were then subjected to statistical analyses, which are presented below.

\section{Primary comparisons}

Confirmation-test versus contrast-test (Comparison 1) The first inclusive model revealed a Time Window $\times$ Empathy $\times$ Condition interaction $\left(\beta=-2.617, t=-2.947, p_{\text {adj }}<.05\right)$, a Time Window $\times$ Condition $\times$ Time interaction $(\beta=-2.419, t$ $\left.=-5.675, p_{\text {adj }}<.001\right)$, and a Time Window $\times$ Empathy $\times$ Time interaction $\left(\beta=1.794, t=3.848, p_{\text {adj }}<.001\right)$. In all three interactions, the significant differences were found between the $0-675 \mathrm{~ms}$ and the $675-1,400 \mathrm{~ms}$ windows. The inspection within the relevant time windows shows that empathy, condition, and time interacted in the $0-675 \mathrm{~ms}$ window $(\beta=0.267, t$ $\left.=3.802, p_{\mathrm{adj}}<.001\right)$, while in the $675-1,400 \mathrm{~ms}$ time window, time only interacted either with empathy $(\beta=2.353, t=3.515$, $\left.p_{\text {adj }}<.001\right)$ or with condition $\left(\beta=-4.527, t=-7.398, p_{\text {adj }}<\right.$ $.001)$. These results reveal that during the unfolding of the ambiguous word, listeners directed their gaze patterns at distinct images depending on the intonation contour they were exposed to and as a function of their empathy level. Then, during the subsequent disambiguation portion, condition and empathy influenced listeners' fixations.

Contrast-test versus contrast-control (Comparison 2) The first inclusive model revealed a Time Windows $\times$ Condition $\times$ Empathy $\times$ Time interaction $\left(\beta=-1.414, t=-3.524, p_{\text {adj }}\right.$ $<.001$, for the $0-675-\mathrm{ms}$ vs. 675-1,400-ms comparison), a Time Window $\times$ Empathy $\times$ Time interaction $(\beta=-1.477$, $t=-3.257, p_{\text {adj }}<.01$, for the $0-675-\mathrm{ms}$ vs. $1,400-1,900-$ ms comparison), and a Time Window $\times$ Condition $\times$ Time interaction $\left(\beta=2.399, t=6.515, p_{\text {adj }}<.001\right.$, for the 0 675-ms vs. 675-1,400-ms comparison; $\beta=2.711, t=$ $6.515, p_{\text {adj }}<.001$, for the $0-675$-ms vs. $1,400-1,900-\mathrm{ms}$ comparison). A closer inspection within the relevant time windows revealed a Condition $\times$ Time interaction $(\beta=$ $\left.5.164, t=8.35, p_{\text {adj }}<.001\right)$ as well as an Empathy $\times$ Time interaction $\left(\beta=0.22, t=3.285, p_{\text {adj }}<.01\right)$ in the $0-675-\mathrm{ms}$ window, while in the subsequent $675-1,400-\mathrm{ms}$ time window we found an Empathy $\times$ Condition $\times$ Time interaction $\left(\beta=1.948, t=3.562, p_{\text {adj }}<.001\right)$. These results reveal that during the critical word listeners fixated different images depending both on the condition and on their empathy level. Then, during the first portion of the disambiguation, the distinct fixations across conditions were modulated by the listeners' empathy level.

\section{Additional comparisons}

Contrast-control and contrast-filler (Comparison 3) The first inclusive model revealed a Time Window $\times$ Empathy $\times$ Time interaction $\left(\beta=4.236, t=2.971, p_{\text {adj }}<.05\right.$ for the $0-675-\mathrm{ms}$ vs. 675-1,400-ms comparison). An inspection of the relevant time windows shows an Empathy $\times$ Time interaction in the 0 675-ms time window $\left(\beta=-4.768, t=-3.038, p_{\text {adj }}<.05\right)$. 
These results indicate that empathy modulates listeners' fixations during the critical word processing, independently of whether the previous context was lexically ambiguous or not.

\section{Confirmation-test versus confirmation-filler (Comparison 4)} The first inclusive model revealed a Time Window $x$ Condition $\times$ Empathy $\times$ Time interaction $(\beta=-1.272, t=$ $-3.757, p_{\text {adj }}<.001$ for the $0-675$-ms vs. $675-1,400-\mathrm{ms}$ comparison), and a Time Window $\times$ Condition $\times$ Time interaction $\left(\beta=-1.649, t=-5.310, p_{\text {adj }}<.001\right.$, for the $0-675$-ms vs. $675-1,400$-ms comparison; $\beta=-2.488, t=$ $-7.118, p_{\text {adj }}<.001$, for the $0-675-\mathrm{ms}$ vs. $1,400-1,900-\mathrm{ms}$ comparison). The inspection to the relevant windows shows a Condition $\times$ Empathy $\times$ Time interaction in the $0-675$-ms time window $\left(\beta=2.333, t=4.500, p_{\text {adj }}<.001\right)$, while condition was a main effect in the subsequent time windows $\left(\beta=4.328, t=3.250, p_{\text {adj }}<.01\right.$, in the $0-675-\mathrm{ms}$ window; $\beta=9.407, t=1.340, p_{\text {adj }}<.001$ in the $675-$ 1,400-ms window). This comparison shows that fixations toward the target varied in these two conditions as a function of the listeners' empathy score, but that once the disambiguating material was presented, these two conditions elicited distinct fixations toward the target independently of the listeners' empathy level.

\section{Summary of the eye-tracking results}

Comparison 1 showed that the listeners' empathy level affected the processing of an ambiguous word, when intonation was the only cue that could be used to disambiguate the target. Figure 3 shows that although less empathic listeners looked at the suggested image equally in the two conditions during the $0-675-\mathrm{ms}$ window, highly empathic listeners' looking patterns differed across conditions because they looked at the suggested image less often in the confirmation-test condition. Given that this pattern goes against our expectations, we designed a post hoc behavioral task to explore the intonation-meaning associations across empathy scores (see next section). In subsequent time windows, once the referent was overtly (lexically) disambiguated, all participants looked at the relevant AoI in each condition. Comparison 2 further supports the claim that empathy matters to the processing of intonation by showing an empathy effect even if the response contains a nonambiguous critical word. The Empathy $\times$ Time interaction during the unfolding of the critical word shows that highly empathic listeners looked more at the suggested image in both conditions, and did so even if there were unambiguous segmental cues indicating that it was the incorrect referent.

Additional comparisons showed that empathy modulates listeners' fixations during the critical word processing independently of the nature of previous sentence context (Comparison 3), and that confirmed that the effect of empathy is stronger when there is linguistic ambiguity (Comparison 4), as listeners with higher empathy looked less at the target when the critical word was ambiguous, but that this influence disappears in subsequent disambiguating portions.

\section{Post hoc behavioral task}

Comparison 1 in the eye-tracking data showed that empathy impacted on how listeners processed intonation, and Fig. 3 illustrates that less empathic individuals did not vary their looking behavior as a function of intonation cues, while highly empathic individuals did. Importantly, the direction of the looking behavior in the highly empathic individuals was intriguing: Confirmation intonation was expected to imply confirmation meaning and thus to elicit more looks at the suggested image, whereas contrast intonation was expected to trigger a contrast meaning and thus to elicit more looks at other AoIs. And yet the reverse intonation-meaning mapping was observed in highly empathic listeners.

These results could have two explanations: It could be that highly empathic listeners map intonation contours to less plausible meaning interpretations, or instead it could be that highly empathic listeners were considering all the possible alternative meanings while still mapping intonation to the most plausible interpretation. We designed an off-line task to investigate these possibilities. Participants listened only to the ambiguous portion of the same test sentences as in the eye-tracking task (we cut sentences at the beginning of the segmental disambiguation), and had to match them to either a confirmatory or a contrast meaning. If the first explanation is true, we would expect higher-empathy listeners to choose the contrast meaning after hearing the confirmatory LHiL* L\% falling intonation, and vice-versa. If the second explanation is true, we expect all listeners to prefer contrast meaning for contrast intonation, and confirmatory meanings upon being exposed to confirmation intonation.

A matching task was presented to 21 French-speaking participants using the Surveygizmo online application. The task consisted of 36 trials (18 critical trials and 18 filler trials), with materials adapted from the visual-world eye-tracking experiment. As in the eye-tracking task, in each trial participants were first presented with a Player A's guess accompanied by the left image in Fig. 2, and afterward they were presented with Player B's audio response now accompanied by two pictures depicting each possible interpretation of the homophone pair. All guesses and responses were equal to the eyetracking task, but now the responses did not contain the disambiguation phrase and thus ended at the end of the critical word, as in the following. 
Speaker A's suggestion: Je pense que tu as une cane

"I think you have a female duck."

Speaker B's response: J'ai un/e canne $L H^{*} L-L \%$

"I have a stick."

In total, participants were presented with 18 confirmation trials (12 confirmation-fillers and six confirmation-test) and 18 contrast trials (six contrast-fillers, six contrast-control, and six contrast-test). Listeners had to click on the interpretation they found more plausible. Before completing the intonation-meaning-matching task, participants filled in the French version of the EQ Questionnaire (Baron-Cohen \& Wheelwright, 2004), as in the eye-tracking task.

A mixed-effects logistic regression model (with participants and items as random effects to accommodate byparticipant and by-item variation; Baayen, 2008; Barr et al., 2013; Jaeger, 2008) was applied to the participants' responses in the critical trials using the lmer package in the R platform. The dependent variable was appropriate response (1 if participants chose the expected response in each condition, and 0 if they did not), while fixed factors were empathy (continuous) and test condition (two levels: confirmation-test, contrasttest). ${ }^{3}$ Results showed a main effect of empathy $(\beta=$ $0.02397, z=2.240, p<.05)$, a marginal effect of condition $(\beta=0.6265, z=-1.782, p=.07)$, and no interaction between empathy and condition $(\beta=-0.03586, z=1.386, p=.16)$. These findings show that empathy impacted both conditions: the higher the listeners' empathy the more they preferred the appropriate response. Interestingly, an inspection to Fig. 4 shows that less empathic individuals preferred a contrast interpretation independently of the intonation contour: They appropriately chose contrast meaning for contrast intonation $60 \%$ of the time, and also inappropriately chose the contrast meaning for confirmation intonation $60 \%$ of the time. Because Speaker A's guesses were always accompanied by an image of the nondominant interpretation of the homophonous word, preferring a contrast interpretation for Speaker B's response could indicate a bias for the dominant (most frequent) interpretation of the homophonous word. We therefore propose that less empathic individuals ignored intonation cues and based their answers on frequency effects.

The off-line task confirmed that highly empathic listeners appear to map intonation cues to the most plausible meaning. In the eye-tracking data, we also observed that highly empathic individuals looked more at the inappropriate AoI during the processing of each critical intonation contour, we therefore suggest that these listeners map intonation to the most plausible meaning yet still consider the set of all possible alternatives.

\footnotetext{
3 glmer(Appropriate Response $\sim$ empathy $\times$ condition $+($ empathy $\mid$ item $)+$ (condition|participant), data).
}

\section{Discussion}

By means of a visual-world eye-tracking task, this study aimed at investigating how individual empathy skills affect the online processing of sentence meaning, when lexical cues are temporarily ambiguous and accompanying cues like intonation can be used to disambiguate a speaker's intentions. We hypothesized that individuals with higher empathy (greater pragmatic skills) would use intonation to form hypotheses about the most plausible interpretation of ambiguous lexical cues, and that individuals with higher empathy would be more likely to activate and maintain all the potential alternative interpretations of temporary ambiguous words.

Our main result is that individual empathy influences the processing of intonation-meaning associations: Less empathic individuals did not disambiguate an ambiguous referent on the basis of the intonation they perceived, while individuals with higher empathy skills formed distinct associations depending on the intonation cues accompanying the ambiguous critical word. Previous studies have reported an effect of individual pragmatic skills on intonation processing and on the type of prosodic events that are relevant for sentence processing (Bishop, 2016; Bishop \& Kuo, 2016; Bishop et al., 2015; Diehl et al., 2008; Jun \& Bishop, 2014). Our results are in line with this proposal, and we further show that listeners with better pragmatic abilities process tonal information to form intonation-meaning associations in the presence of lexical ambiguity, whereas less empathic individuals wait for lexical disambiguation to be presented.

The specificity of French prosodic structure might have highlighted the effect of empathy. Hexagonal French is a language with fixed stress, in which nuclear tonal information generally occurs during the last full syllable of the phrase (Jun \& Fougeron, 2000, 2002). In other languages, such as English or Spanish, the position of the stressed syllable is not fixed and can occur at prefinal positions, thus allowing segmental material to occur between the pitch accent and right-edge boundary tone (Jun, 2005). Hence, if listeners used intonation cues to disambiguate meaning in our eye-tracking task, they had to do it very quickly, before subsequent lexical disambiguating material was presented, and maybe only pragmatically skilled individuals are able to do so.

Interestingly, highly empathic listeners used tonal events in the nonexpected direction (i.e., looking at the suggested image when intonation was contrastive, but not looking at it when intonation was confirmatory). One possibility, which we argued is not supported by the results of the post hoc task, was that individuals with higher empathy stopped looking at the image that was suggested upon hearing confirmation 


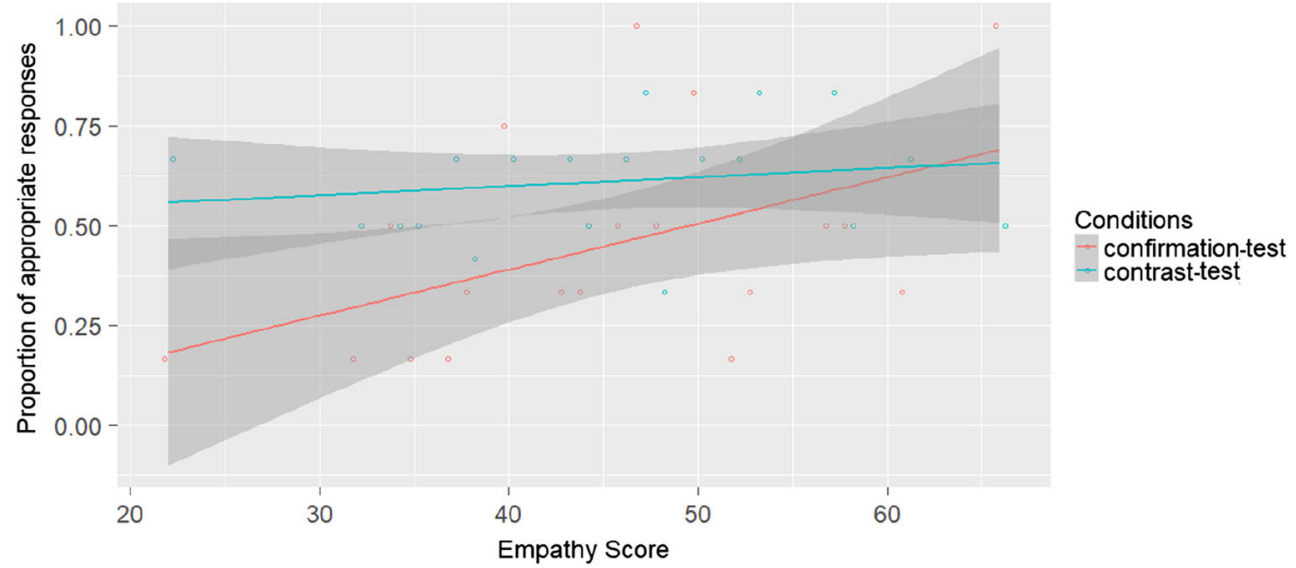

Fig. 4 Accuracy in selecting the appropriate response in each test condition as a function of the listeners' empathy score

intonation simply because they interpreted the falling contour as signaling contrast of beliefs instead of confirmation. This account would be in line with previous results reporting that in French (as in many other languages) there is no absolute oneto-one intonation-meaning mapping (Katz \& Selkirk, 2011; Portes et al., 2014; Ward \& Hirschberg, 1988). Results of the post hoc task did not show that highly empathic individuals favor an unexpected mapping between intonation and meaning, and therefore we propose that the lack of one-to-one intonation-meaning mapping reported in the literature for other intonation contours does not explain our results.

Another possibility, however, was that highly empathic individuals mapped tunes to meanings as expected, but that they were more sensitive to all the meaning alternatives of a given referent and therefore fixated them when the critical word was presented. We propose that the post hoc behavioral task confirmed this second prediction: Highly empathic listeners associate contrast intonation with an appropriate contrastive interpretation (and the reverse for the confirmation intonation). Listeners with higher empathy skills consider the set of all possible alternatives while still mapping intonation to the most plausible meaning. Previous eyetracking research has shown that listeners activate the set of alternatives when processing a contrastively focused element (e.g., Braun \& Tagliapietra 2010; see Gotzner, 2015, for an overview), and that they can look at the negated referent when computing negation (Orenes, Beltrán, \& Santamaría, 2014; Shuval \& Hemforth, 2008). Additionally, we know that individuals with higher perspective-taking abilities are more sensitive to all possible alternative interpretations of an implicature, and more eager to interpret them in a pragmatically enriched way (Bott \& Noveck, 2004; Degen \& Tanenhaus, 2015; Li et al., 2014).

The present study evaluated empathy as a source of individual variability in the processing of intonation to resolve sentence ambiguity. Empathy is part of the set of pragmatic abilities that enable listeners to understand the communicative intentions and feelings behind the interlocutor's words (Baron-Cohen \& Wheelwright, 2004). Our study provides evidence that listeners make use of these abilities when processing linguistic information, especially when this information is ambiguous or nonliteral. We show that empathy influences how we evaluate the alternatives of ambiguous information, and how we use features accompanying lexical-semantic material, like intonation, to infer pragmatic meaning. Because of the task constraints, and because of the nature of the questionnaire, we cannot distinguish whether it is the affective or the cognitive component of empathy that triggers our findings (Zaki \& Ochsner, 2012). Although both components are intertwined and co-occur (Baron-Cohen \& Wheelwright, 2004), future studies could use more precise measures to find out whether they equally influence the processing of intonational and linguistic information.

Communicative exchanges require listeners to understand the pragmatic intentions behind the interlocutor's speech acts, and our skills in inferring others' social and pragmatic states seem to affect this linguistic understanding. Individual pragmatic and social skills are also a good indicator of language and cognitive impairments (e.g., Baron-Cohen, 1989; Perner, Frith, Leslie, \& Leekam, 1989), and their specific training results in improvement of the socially related behavior (Peters \& Thompson, 2018). Our study shows that individual variability in terms of social and pragmatic skills needs to be considered when investigating the online processing of intonation and meaning in typical populations as well. Only then will we have a more complete picture of how listeners are able to infer communicative intentions and utterance meaning from intonational speech cues.

Acknowledgments We thank Caterina Petrone and Yair Haendler for their advice for the statistical analyses. An earlier version of this work was presented at Speech Prosody 2016. We thank the reviewers of that conference for their helpful comments as well as the anonymous reviewers of this journal, which have led to considerable improvement of the present paper. 
Open practices statement Neither of the experiments reported in this article was formally preregistered. Neither the data nor the materials have been made available on a permanent third-party archive; requests for the data or materials can be sent via email to the lead author at nesteveg@uoc.edu.

Funding This work, carried out within the Labex BLRI (ANR-11LABX-0036), has benefited from support from the French government, managed by the French National Agency for Research (ANR), under the project title Investments of the Future A*MIDEX (ANR-11-IDEX-000102). We also benefited from a Mercator Fellowship attributed to C.P. by the German Science Foundation (DFG), Sonderforschungsbereich 732 Incremental Specification in Context, Project A6, at the University of Stuttgart. We thank also the IUF (Institut Universitaire de France) for having funded part of this research through a grant attributed to the last author.

\section{References}

Allopenna, P. D., Magnuson, J. S., \& Tanenhaus M. K. (1998). Tracking the time course of spoken word recognition using eye movements: Evidence for continuous mapping models. Journal of Memory and Language, 38(4), 419-439.

Altmann, G. T. M., \& Kamide, Y. (2004). Now you see it, now you don't: Mediating the mapping between language and the visual world. In J. H. Henderson \& F. Ferreira (Eds.), The interface of language, vision, and action: Eye movements and the visual world (pp. 347-386). New York, NY: Psychology Press.

Baayen, R. H. (2008). Analyzing linguistic data: A practical introduction to statistics using $R$. Cambridge, England: Cambridge University Press.

Baron-Cohen, S. (1989). Perceptual role-taking and protodeclarative pointing in autism. British Journal of Child Psychology and Psychiatry, 30, 285-298.

Baron-Cohen, S. (2011). Zero degree of empathy: On empathy and the origins of cruelty. London, England: Penguin.

Baron-Cohen, S., Leslie, A. M., \& Frith, U. (1985). Does the autistic child have a "Theory of Mind"? Cognition, 21, 37-46.

Baron-Cohen, S., \& Wheelwright, S. (2004). The empathy quotient: An investigation of adults with Asperger syndrome or high functioning autism, and normal sex differences. Journal of Autism and Developmental Disorders, 34(2), 163-175.

Baron-Cohen, S., Wheelwright, S., Skinner, R., Martin, J., \& Clubley, E. (2001). The Autism-Apectrum Quotient (AQ): Evidence from Asperger syndrome/high-functioning autism, males and females, scientists and mathematicians. Journal of Autism and Developmental Disorders, 31, 5-17.

Barr, D. J., Levy, R., Scheepers, C., \& Tily, H. J. (2013). Random effects structure for confirmatory hypothesis testing: Keep it maximal. Journal of Memory and Language, 68(3), 255-278.

Bates, D., Maechler, M., Bolker, B., \& Walker, S. (2014). lme4: Linear mixed-effects models using Eigen and S4 [Computer software]. Retrieved from https://cran.r-project.org/web/packages/lme4/index. html

Bates, D., Kliegl, R., Vasishth, S., \& Baayen, H. (2015). Parsimonious mixed models. Retrieved from https://arxiv.org/abs/1506.04967

Bishop, J. (2016). Individual differences in top-down and bottom-up prominence perception. Proceedings of Speech Prosody, 2016, $668-672$.

Bishop, J., Chong, A., \& Jun, S.-A. (2015, August). Individual differences in prosodic strategies to sentence parsing. Paper presented at the 18th International Congress of Phonetic Sciences, Glasgow, Scotland.

Bishop, J., \& Kuo, G. (2016, July). Do "autistic-like" personality traits predict prosody perception? Talk presented at LabPhon 15 Satellite Workshop on Personality in Speech Perception and Production, Ithaca, NY.

Boersma, P., \& Weenink, D. (2012). Praat: Doing phonetics by computer [Computer software]. Retrieved from http://www.praat.org/

Bott, L., \& Noveck, I. A. (2004). Some utterances are underinformative: The onset and time course of scalar inferences. Journal of Memory and Language, 51, 437-457.

Braun, B., \& Tagliapietra, L. (2010). The role of contrastive intonation contours in the retrieval of contextual alternatives. Language and Cognitive Processes, 25, 1024-1043.

Cain, K., Lemmon, K., \& Oakhill, J. (2004). Individual differences in the inference of word meanings from context: The influence of reading comprehension, vocabulary knowledge, and memory capacity. Journal of Educational Psychology, 96(4), 671-681.

Carruthers, P. (2009). How we know our own minds: The relationship between mindreading and metacognition. Behavioral and Brain Sciences, 32(2), 121-182.

Chen, A., Gussenhoven, C., \& Rietveld, T. (2004). Language-specificity in the perception of paralinguistic intonational meaning. Language and Speech, 47(4), 311-350.

Chen, L., \& Boland, J. E. (2008). Dominance and context effects on activation of alternative homophone meanings. Memory \& Cognition, 36, 1306-1323.

Chu, M., Meyer, A., Foulkes, L., \& Kita, S. (2014). Individual differences in frequency and saliency of speech-accompanying gestures: The role of cognitive abilities and empathy. Journal of Experimental Psychology: General, 143(2), 694-709.

Cutler, A., Dahan D., \& van Donselaar, W. (1997). Prosody in the comprehension of spoken language: A literature review. Language and Speech, 40, 141-201.

Dahan, D., Tanenhaus, M. K., \& Chambers, C. G. (2002). Accent and reference resolution in spoken-language comprehension. Journal of Memory and Language, 47, 292-314.

Davis, M. H. (1980). A multidimensional approach to individual differences in empathy. JSAS Catalog of Selected Documents in Psychology, 10, 85.

Degen, J., \& Tanenhaus, M. K. (2015). Availability of alternatives and the processing of scalar implicatures: A visual world eye-tracking study. Cognitive Science, 40(1), 1-30. Advance online publication. https:// doi.org/10.1111/cogs. 12227

Delais-Roussarie, E., Post, B., Avanzi, M., Buthke, C., Di Cristo, A., Feldhausen, I., ... Yoo, H.-Y. (2015). Intonational phonology of French: Developing a ToBI system for French. In S. Frota \& P. Prieto (Eds.), Intonation in romance (pp. 63-100). Oxford, England: Oxford University Press.

Delattre, P. (1966). Les dix intonations de base du français [The ten basic intonations of French]. The French Review, 40, 1-14.

Diehl, J. J., Bennetto, L., Watson, D., Gunlogson, C., \& McDonough, J. (2008). Resolving ambiguity: A psycholinguistic approach to understanding prosody processing in high-functioning autism. Brain and Language, 106(2), 144-152.

Dink, J. W., \& Ferguson, B. (2015). eyetrackingR: An R library for eyetracking data analysis [Computer software]. Retrieved from eyetracking-r.com

Estebas-Vilaplana, E., \& Prieto, P. (2010). Peninsular Spanish intonation. In P. Prieto \& P. Roseano (Eds.), Transcription of intonation of the Spanish language (pp. 17-48). Munich, Germany: Lincom Europe.

Foucart, A., Garcia, X., Ayguasanosa, M., Thierry, G., Martin, C., \& Costa, A. (2015). Does the speaker matter? Online processing of semantic and pragmatic information in L2 speech comprehension. Neuropsychologia, 75, 291-303. 
Friedman, N. P., Miyake, A., Young, S. E., DeFries, J. C., Corley, R. P., \& Hewitt, J. K. (2008). Individual differences in executive functions are almost entirely genetic in origin. Journal of Experimental Psychology: General, 137(2), 201-225.

Frith, U., \& Frith, C. D. (2003). Development and neurophysiology of mentalizing. Philosophical Transactions of the Royal Society B., 358(1431), 459-473.

Frota, S., \& Prieto, P. (Eds.). (2015). Intonation in Romance. Oxford, England: Oxford University Press.

Gandour, J., Wong, D., \& Hutchins, G.D. (1998). Pitch processing in the human brain is influenced by language experience. NeuroReport, 9 , $2115-2119$.

Gotzner, N. (2015). Establishing alternative sets (Unpublished doctoral dissertation). Humboldt University of Berlin.

Huettig, F., \& Altmann, G. T. (2007). Visual-shape competition during language-mediated attention is based on lexical input and not modulated by contextual appropriateness. Visual Cognition, 15(8), 9851018.

Ito, K., \& Speer, S. R. (2008). Anticipatory effects of intonation: Eye movements during instructed visual search. Journal of Memory and Language, 58(2), 541-573.

Jaeger, T. F. (2008). Categorial data analysis: Away from ANOVAs (transformation or not) and towards logit mixed models. Journal of Memory and Language, 59, 434-446.

Jun, S.-A. (2005). Introduction. Prosodic typology: The phonology of intonation and phrasing. Oxford, England: Oxford University Press.

Jun, S., \& Bishop, J. (2014). Implicit prosodic priming and autistic traits in relative clause attachment. In Proceedings of the Conference on Speech Prosody. Dublin, Ireland.

Jun, S.-A., \& Fougeron, C. (2000). A phonological model of French intonation. In Botinis, A. (Ed.), Intonation: Analysis, models and technology (pp. 209-242). Dordrecht: Kluwer.

Jun, S.-A., \& Fougeron, C. (2002). Realizations of accentual phrase in French intonation. Probus, 14, 147-172.

Just, M. A., \& Carpenter, P. A. (1992). A capacity theory of comprehension: Individual differences in working memory. Psychological Review, 99, 122-149.

Katz, J., \& Selkirk, E. (2011). Contrastive focus vs. discourse-new: Evidence from phonetic prominence in English. Language, 87(4), 771-816.

Kidd, E., Donnelly, S., \& Christiansen, M. H. (2018). Individual differences in language acquisition and processing. Trends in Cognitive Sciences, 22(2), 154-169.

Kuznetsova, A., Brockhoff, P. B., \& Christensen, R. H. B. (2017). lmerTest package: Tests in linear mixed effects models. Journal of Statistical Software, 82(13), 1-26.

Ladd, D. R. (2008). Intonational phonology. Cambridge, England: Cambridge University Press. (Original work published 1996)

Li, S., Jiang, X., Yu, H., \& Zhou, X. (2014). Cognitive empathy modulates the processing of pragmatic constraints during sentence comprehension. Social Cognitive and Affective Neuroscience, 9, 11661174.

Matin, E., Shao, K. C., \& Boff, K. R. (1993). Saccadic overhead: Information-processing time with and without saccades. Perception \& psychophysics, 53(4), 372-380.

Miles, W. R. (1929). Ocular dominance demonstrated by unconscious sighting. Journal of Experimental Psychology, 12, 113-126.

Mirman, D. (2014). Growth curve analysis and visualization using $R$. Chapman and Hall / Boca Raton, FL: CRC Press.

Mirman, D., Dixon, J. A., \& Magnuson, J. S. (2008). Statistical and computational models of the visual world paradigm: Growth curves and individual differences. Journal of Memory and Language, 59, 475-494.

Münster, K., \& Knoeferle, P. (2018). Extending situated language comprehension (accounts) with speaker and comprehender characteristics: Toward socially situated interpretation. Frontiers in Psychology, 8, 1-12.

Nash, J. C., \& Varadhan, R. (2011). Unifying optimization algorithms to aid software system users: optimx for R. Journal of Statistical Software, 43(9), 1-14.

New, B., Pallier, C., Brysbaert, M., \& Ferrand, L. (2004). Lexique 2: A new French lexical database. Behavior Research Methods, Instruments, \& Computers, 36(3), 516-524.

Nieuwland, M. S., Ditman, T., \& Kuperberg, G. R. (2010). On the incrementality of pragmatic processing: An ERP investigation of informativeness and pragmatic abilities. Journal of Memory and Language, 63(3), 324-346.

Orenes, I., Beltrán, D., \& Santamaría, C. (2014). How negation is understood: Evidence from the visual world paradigm. Journal of Memory and Language, 74, 36-45.

Perner, J., Frith, U., Leslie, A. M., \& Leekam, S. (1989). Exploration of the autistic child's theory of mind: Knowledge, belief, and communication. Child Development, 60, 689-700.

Peters, L. C., \& Thompson, R. H. (2018). How teaching perspective taking to individuals with autism spectrum disorders affects social skills: Findings from research and suggestions for practitioners. Behavior Analysis in Practice, 11(4), 467-478.

Pierrehumbert, J., \& Hirschberg, J. (1990). The meaning of intonational contours in interpretation of discourse. In P. Cohen, J. Morgan, \& M. Pollack (Eds.), Intentions in communication (pp. 273-311). Cambridge, MA: MIT Press.

Portes, C. (2004). Prosodie et économie du discours: Spécificité phonétique, écologie discursive et portée pragmatique de l'intonation d'implication [Prosody and discourse economics: Phonetic specificity, discursive ecology and pragmatic scope of implicit intonation] (Doctoral dissertation, Aix-Marseille Université).

Portes, C., Beyssade, C., Michelas, A., Marandin, J.-M., \& ChampagneLavau, M. (2014). The dialogical dimension of intonational meaning: Evidence from French. Journal of Pragmatics, 74, 15-29.

Portes, C., \& Reyle, U. (2014, May). The meaning of French "implication" contour in conversation. Paper presented at the 7 th International Conference on Speech Prosody, Dublin, Ireland.

Prieto, P. (2015). Intonational meaning. Wiley Interdisciplinary Reviews: Cognitive Science, 6, 371-381.

Rockwell, P. (2003). Empathy and the expression and recognition of sarcasm by close relations or strangers. Perceptual and Motor Skills, 97, 251-256.

Salverda, A. P., Kleinschmidt, D., \& Tanenhaus, M. K. (2014). Immediate effects of anticipatory coarticulation in spoken-word recognition. Journal of Memory and Language, 71, 145-163.

Shamay-Tsoory, S. G., Aharon-Peretz, J., \& Perry, D. (2009). Two systems for empathy: A double dissociation between emotional and cognitive empathy in inferior frontal gyrus versus ventromedial prefrontal lesions. Brain, 132(3), 617-627.

Shuval, N., \& Hemforth, B. (2008). Accessibility of negated constituents in reading and spoken language comprehension. Journal of Intercultural Pragmatics, 5(4), 445-469.

Swets, B., Desmet, T., Hambrick, D. Z., \& Ferreira, F. (2007). The role of working memory in syntactic ambiguity resolution: A psychometric approach. Journal of Experiment Psychology: General, 136(1), 64 81.

Tanenhaus, M. K., Spivey-Knowlton, M. J., Eberhard, K. M., \& Sedivy, J. C. (1995). Integration of visual and linguistic information in spoken language comprehension. Science, 268, 1632-1634.

Van den Brink, D., Van Berkum, J. J. A., Bastiaansen, M. C. M., Tesink, C. M. J. Y., Kos, M., Buitelaar, J. K., \& Hagoort, P. (2012). Empathy matters: ERP evidence for inter-individual differences in social language processing. Social Cognitive and Affective Neuroscience, 7, 173-183. 
Ward, G., \& Hirschberg, J. (1988). Intonation and propositional attitude: The pragmatics of $\mathrm{L}^{*}+\mathrm{HLH} \%$. Proceedings of the Fifth Eastern States Conference on Linguistics, Philadelphia, 512-522.

Wickham, H. (2016). ggplot2: Elegant graphics for data analysis. Cham, Switzerland: Springer.

Wimmer, H., \& Perner, J. (1983). Beliefs about beliefs: Representation and constraining function of wrong beliefs in young children's understanding of deception. Cognition, 13, 103-128.
Zaki, J., \& Ochsner, K. N. (2012). The neuroscience of empathy: Progress, pitfalls and promise. Nature Neuroscience, 15, 675-680.

Zhao, M., Liu, T., Chen, G., \& Chen, F. (2015). Are scalar implicatures automatically processed and different for each individual? A mismatch negativity (MMN) study. Brain Research, 1599, 137-149.

Publisher's note Springer Nature remains neutral with regard to jurisdictional claims in published maps and institutional affiliations. 